\title{
Diffuse Peritonitis Associated With Ventral Hernia In An Adult Doe: Case Report
}

\author{
${ }^{1}$ Kimeli, P*., ${ }^{1}$ Kipyegon, A.N., ${ }^{1}$ Mwangi, W. E., ${ }^{1}$ Mogoa, E.G.M., ${ }^{2}$ Karanja D.N. \\ ${ }^{I}$ Department of Clinical Studies, \\ ${ }^{2}$ Department of Veterinary Pathology. Microbiology and Parasitology, \\ Faculty of Veterinary Medicine, University of Nairobi,P.O. Box 29053-00625 Kangemi, Kenya.
}

\begin{abstract}
A case of diffuse fibrino-purulent peritonitis associated with ventral abdominal hernia is reported in an adult non-descript doe. The affected animal was noticed to have developed a swelling on the left ventrolateral aspect of the abdomen a day after parturition and inappentance two weeks later. Clinical examination revealed dyspnea, dullness and shivering. The rectal temperature was $37.2^{\circ} \mathrm{C}$ and respiratory rate 42 breathes per minute. There was a swelling on left ventral abdomen with a palpable ring at its base. Ultrasonography confirmed the presence of intestinal loops in the swelling and hematology revealed severe leukocytosis, lymphopenia and decreased hematocrit. Initial medical management was undertaken for five days before herniorrhaphy. Celiotomy revealed one liter of straw-colored peritoneal fluid, extensive intra-abdominal adhesions and diffuse fibrin formation with multiple pockets of pus. Despite aggressive efforts to manage this condition, the animal died four hours after surgery. Autopsy revealed purulent exudates in the subcutis and abdominal muscles peripheral to the corrected ventral hernia.
\end{abstract}

Key Words: fibrin-purulent peritonitis, septicemia, hypothermia, hernia

\section{Introduction}

Herniation refers to protrusion of an organ or tissue through an opening that may be natural or caused by a tear in the abdominal wall (Jettennavar et al., 2010). Ventral abdominal hernia is a commonly acquired condition in small ruminants (Abdin-Bey and Ramadan 2001) caused by the migration of viscera through a tear in the abdominal wall (Das, 2012). The tear may be dorsal or ventral in the flank, along the costal arch or between the last few ribs (Fahd and Ahmed, 2007). Ventral hernias in small ruminants commonly result from traumas caused by horn thrust, kick or violent contact with blunt objects or by an abdominal distension due to pregnancy or violent straining during parturition (Das et al, 2012; Jettennavar et al, 2010).

Abdominal hernias have been documented to have good post-surgical outcomes with excellent surgical wound healing (Fahd and Ahmed, 2007). However, complicated cases presents with poor prognosis (Fahd and Ahmed, 2007). Reported complications include; adhesions (Witte, 2008; Alsobayil, 2007), intestinal incarceration (Witte, 2008) and hysterocele (Vijayanand, 2009; Abdin-bey, 2001). This study reports a case of diffuse fibrino-purulent peritonitis associated with ventral abdominal hernia in an adult doe.

\section{Case history, findings and management}

A non-descript doe aged two and half years was presented to the Large Animal Clinic, University of Nairobi, with a history of sudden development of a swelling on the left ventro-lateral aspect of the abdomen a day after parturition. The case was reported two weeks after it occurred. Upon clinical examination, there was labored breathing, dullness and shivering. The rectal temperature was $37.2^{\circ} \mathrm{C}$ and respiratory rate 42 breathes per minute. The swelling on left ventral abdomen was of medium consistency on palpation and measured about $15 \mathrm{~cm}$ in diameter (Fig 1).A ring of about five fingers was palpable at the base of the swelling. Ultrasonography confirmed the presence of intestinal loops in the swelling and hematology revealed severe leukocytosis, lymphopenia and decreased hematocrit (Table 1).

The animal was initially treated using $1000 \mathrm{mg}$ of Procaine Penicillin and $1250 \mathrm{mg}$ of Dihydrostreptomycin sulphate (Norbrook Laboratories Ltd, Station Works Newry) daily for 5 days and $2 \mathrm{mg}$ of Dexamethasone disodium phosphate (Colvasone ${ }^{\circledR}$, Norbrook Laboratories Ltd, Station Works Newry) once, all administered intramuscularly. After 5 days of medical management, the animal stabilized.

Herniorrhaphy was performed (As described by Firth et al, 1985) under Sedation using $2 \mathrm{mg}$ of Xylazine Hcl (Bomazine 2\%, Bomac Laboratories Limited, Auckland- New Zealand) administered intramuscularly and lumbo-sacral epidural anaesthesia using $3 \mathrm{ml}$ of $2 \%$ Lidocaine Hcl(Lidocaine, Mac Pharmaceuticals Limited, Nairobi-kenya). 2000mls of lactated ringers solution (Hartmanns solution, infusion Medicare ltd, Nairobi, Kenya) was administered intravenously throughout the surgery.

Upon celiotomy, about one litre of straw-coloured peritoneal fluid (Fig. 2) was recovered and extensive adhesions noticed. Diffuse fibrin formation with multiple pockets of pus (Fig. 3) was observed on the surfaces 
of intestines, liver, spleen and kidneys. The adhesions were detached and the peritoneal cavity lavaged using warm sterile physiological saline before hernia correction. Despite aggressive efforts to manage this condition, the animal died four hours after surgery.

Autopsy revealed purulent exudates in the subcutis and abdominal muscles peripheral to the corrected ventral hernia.

\section{Discussion}

To the best of researchers' knowledge, this is the first reported case of diffuse fibrino-purulent peritonitis associated with ventral abdominal hernia in a goat with mortality despite attempted management. Over the past years, several cases of both complicated and uncomplicated ventral abdominal hernias in goats have been managed successfully (Alsobayil, 2007; Abdin-bey, 2001).

Uncomplicated ventral abdominal hernia in goats presents with obvious swelling and palpable ring (Jettennavar et al, 2010). On the other hand, complicated ventral abdominal hernias presents with non-specific signs other than the swelling and the ring. In the present case, the animal presented with shivering, hypothermia, labored breathing together with severe leukocytosis, lymphopenia, and decreased hematocrit.

The shivering noted is thought to be a response to hypothermia that is a sequel to persistent septicemia as reported by Steiner et al, (2000). Hypothermia associated with septicemia has been shown to result from hypothalamic dysfunction with alteration in the thermal set point (Marik and Zolaga, 2000) which leads to a loss of reactive peripheral vasoconstriction and shivering. The changes noted on hematology in the current case may also be associated with septicemia.

The authors strongly believed that the current case might have occurred due to multiple causes initiated by a traumatic injury on ventral abdominal wall, which led to the development of an abscess. These coupled with extreme intra-abdominal pressure associated with parturition caused herniation. The contents of the abscess may have spilled into peritoneal cavity and provoked the fibrino-purulent peritonitis noticed in the current study.It is speculated that the unfavorable outcome of the case is due to the extensive organ damage associated with septicemia and renewed inflammatory response following management .

In conclusion, the authors note that diffuse fibrino-purulent peritonitis associated with ventral abdominal hernia can be fatal even with proper patient stabilization. Surgical management of such complicated ventral hernias presents with poor prognosis despite optimal peri-operative practice.

\section{Reference}

[1]. A.A. Fahd and F.A. Ahmed, Surgical Treatment For Different Forms Of Hernias In Sheep And Goats; Journal Veterinary Science, 8(2), 2007,185-191.

[2]. A.A. Steiner, A.Y. Molchanova1, M.D. Dogan, P. Shreya, P. Erika, M. Balask, S. P.Wanner, J. Eales, D. L. Oliveira, N. R. Gavva, M. C. Almeida, M. Sz'ekely and A. A. Romanovsky, The hypothermic response to bacterial lipopolysaccharidecritically depends on brain CB1, but not CB2 or TRPV1, receptors. Journal of Physiology589(9), 2011,2415-2431

[3]. B.C. Das, B.K. Nath, M.S. Pallab, A. Mannan and D. Biswas, Successful management of ventral abdominal hernia in goat: a case report, International Journal of Natural Sciences, 2(2), 2012, 60-62

[4]. E.G. Firth, P. Fontijne, A.W. Kersjes, F. Nemeth, L.J.E. Rutgers and M.A. Van der Velden (Atlas of Large Animal Surgery; First Edition, Williams \& Wilkins Baltimore/ London, 1985)

[5]. F.A. Alsobayil and F.A. Ahmed, Journal of Veterinary Science, 8 (2), 2007, 185-191.

[6]. M.R. Abdin-Bey and R..O.Ramadan, Retrospective Study of Hernias in Goats, Scientific Journal of King Faisal University (Basic and Applied Sciences), 2 (1), 2001, 1421.

[7]. P.E. Marik and G.P. Zaloga, Hypothermia and cytokines in septic shock. Intensive Care Medicine,26, 2000, 716-721

[8]. P.S Jettennavar, G.P. Kalmath and M.C. Anilkumar, Ventral Abdominal Hernia in a Goat; Veterinary World, 3(2), 2010, 93

[9]. Vijayanand, M. Gokulakrishnan, R.C. Rajasundaram and P.S. Thirunavukkarasu, Ventral Hernia (Hysterocele - Gravid) In A Goat A Case Report, Indian Journal of Animal Resource, 43 (2), 2009, 148-150. 
Table 1: Hematology results of the doe that presented with complicated ventral hernia taken on day 0,2 and 6

\begin{tabular}{|c|c|c|c|c|}
\hline Hematological parameters & $\begin{array}{l}\text { Recorded values } \\
\text { on day } 0\end{array}$ & $\begin{array}{l}\text { Recorded } \\
\text { values on day } 2\end{array}$ & $\begin{array}{l}\text { Recorded values } \\
\text { on day } 6\end{array}$ & Normal range \\
\hline White blood cells $\left(\mathrm{m} / \mathrm{mm}^{3}\right)$ & 37.79 & 17.88 & 12.99 & $4.0-13.0$ \\
\hline Lymphocytes (\%) & 37.90 & 38.00 & 48.23 & $50.0-70.0$ \\
\hline Monocytes (\%) & 4.60 & 2.90 & 2.20 & $1.0-4.0$ \\
\hline Granulocytes (\%) & 57.50 & 59.10 & 56.10 & $30.0-56.0$ \\
\hline Red blood cells $\left(\mathrm{m} / \mathrm{mm}^{3}\right)$ & 6.68 & 12.23 & 11.94 & $8.0-18.0$ \\
\hline Mean corpuscular volume (fl) & 20.90 & 17.60 & 16.10 & $16.0-25.0$ \\
\hline Hematocrit $(\%)$ & 13.90 & 21.50 & 23.01 & $22.0-39.0$ \\
\hline Mean corpuscular hemoglobin (pg) & 16.70 & 7.10 & 7.70 & $5.2-8.0$ \\
\hline Mean corpuscular hemoglobin concentration $(\mathrm{g} / \mathrm{dl})$ & 80.50 & 40.90 & 27.40 & $28.0-42.0$ \\
\hline Hemoglobin $(\mathrm{g} / \mathrm{dl})$ & 11.20 & 8.80 & 9.30 & $8.0-12.0$ \\
\hline Thrombocytes $\left(\mathrm{m} / \mathrm{mm}^{3}\right)$ & 304 & 245 & 215 & $200-600$ \\
\hline
\end{tabular}

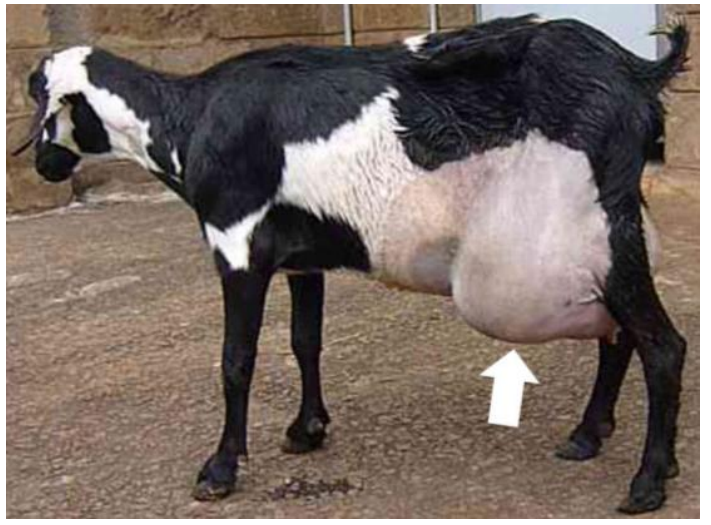

Fig.1: photograph of a doe showing the ventral abdominal hernia

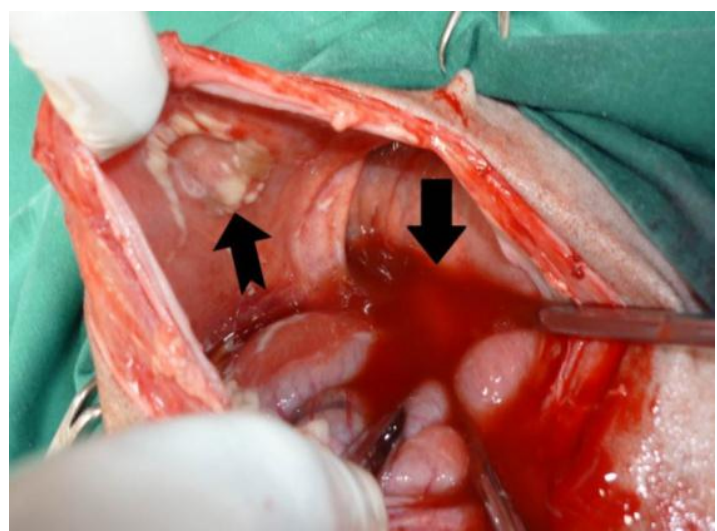

Fig. 2: Photograph showing accumulated peritoneal fluid (bold arrow) and adhesion site on the body wall (notched arrow)

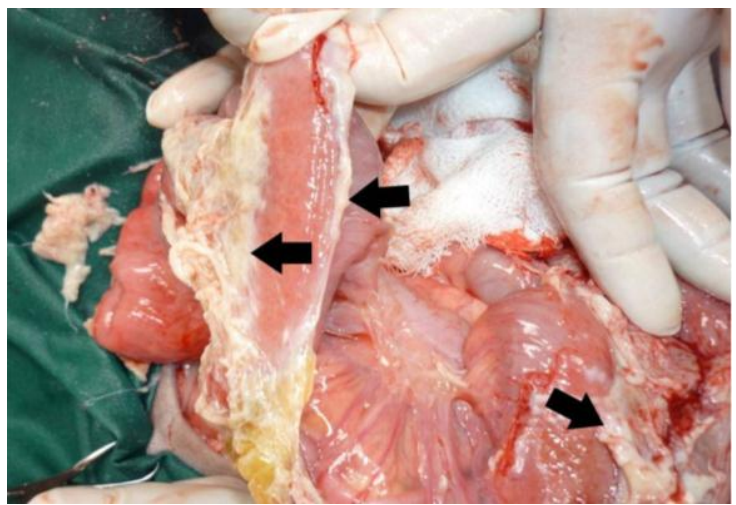

Fig. 3: Photograph showing diffuse fibrin with micro abscesses (bold arrows) on the intestinal serosal surface. 